\title{
Development of Constructions of Mobile Road Overpasses
}

\author{
Adil Kadyrov, Aleksandr Ganyukov and Kyrmyzy Balabekova
}

The Karaganda State Technical University, 100024 Karaganda, Kazakhstan

\begin{abstract}
The new type of engineering constructions that is mobile overpasses is developed. The offered mobile overpasses are applied for elimination the arisen traffic jams along city highways, when repairing city municipal networks, during emergency situations, etc. They allow to carry out continuous movement of motor transport through various obstacles: traffic jams, ditches and trenches formed because of underground repair work or emergency situations (earthquakes, floods, etc.). The issues of development theoretical bases of calculation and design of mobile overpasses are considered.
\end{abstract}

\section{Introduction}

In the conditions of heavy city car traffic there are jams and traffic blocks on roads because of various reasons: car accidents, rush hours, repair work on highways, city municipal networks. In many large cities there is a problem of the solution of jams during everyday traffic and repairing of city infrastructure. For big cities it is a great transport problem. As it is well-known jams and traffic blocks along city highways worsen the transport logistics of the city, ecology, cause economic damage to businessmen, city budget, etc.

For the solution of this problem the design of mobile overpasses is offered by us.
They represent collapsible mobile bridge overpasses which are installed over road strips where there was a traffic block of transport or on the section where there is underground repair of municipal networks under highways that promotes movement of transport on the emergency or repair section and, respectively, eliminates traffic jams and removes the necessity of bypass road of repair sections of roads [1]. (See Fig. 1 and Fig. 2)

Use of the overpasses offered by us considerably improves transport logistics in the city during traffic jams or repair work on municipal networks: formation of traffic jams is reduced, compelled bypass roads of repair sites are absent, inconveniences for car drivers and residents of city districts that can cause the compelled transport bypass are eliminated.

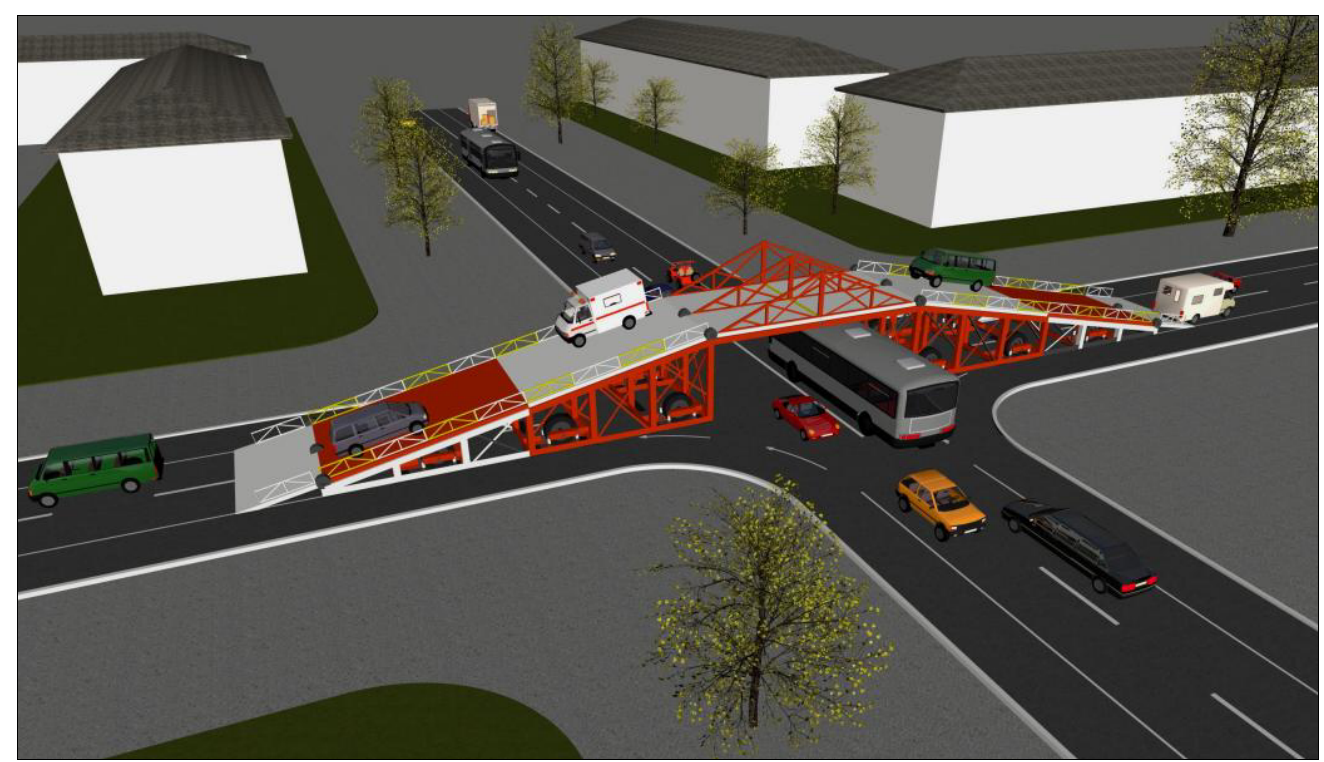

Figure 1. Mobile road overpass 


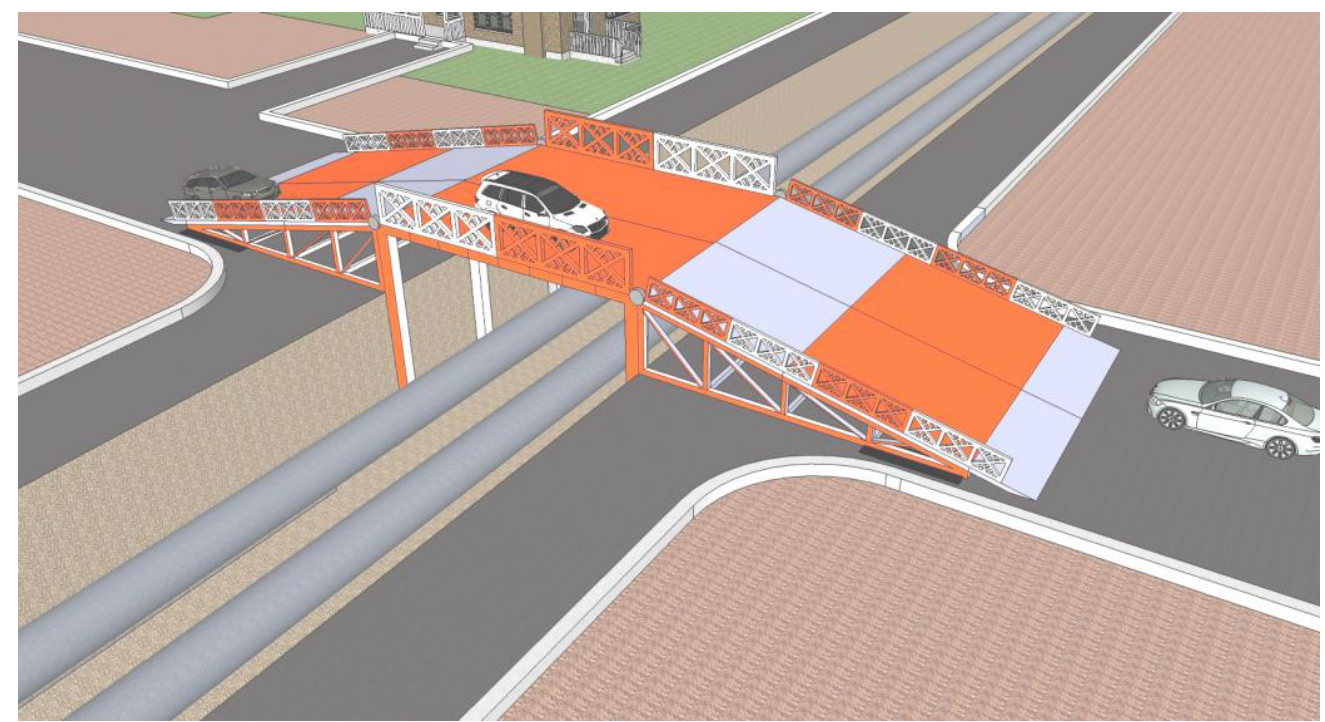

Figure 2. Modular municipal overpass

Such mobile overpasses can be used not only during elimination of traffic jams and at underground repair work in the city conditions, but also during emergency situations caused by flood, earthquake, caused collapse of various infrastructure - roads, bridges, crossings, etc.

Distinctive feature of the offered bridge overpass is its mobility - conveyance on own chassis by means of the automobile trailer or by freight vehicles. Quick assembling and disassembling at the place of its installation due to use of the unified collapsible modules and modes of their fixing between each other and on the ground base. It provides immediate delivery to necessary sites with autojams, repair sites of municipal underground networks or sites with the damaged infrastructure caused by various emergencies [2].

The analysis of the condition of this subject in RK, CIS and abroad showed almost total absence of existence of similar mobile bridge constructions for elimination traffic jams, city repair needs and conditions of emergency.

Separate elements of similar subject are partially developed in military bridge construction - cross over trawls, automobile bridge layers, etc. The matter isn't developed in civil transport engineering and demands comprehensive study and formation of scientific bases of mobile overpasses design for various conditions of their operation. Thus, the mobile overpass has no analogs in the world.

\section{Main results}

\subsection{Types of overpasses}

We offer several versions of overpasses: road, municipal and overpasses for conditions of emergency situations.

The road mobile overpass is intended for elimination traffic jams along city highways. It consists of the horizontal module and two inclined modules equipped with own wheel chassis for transportation and sliding bearing parts. In case of necessity, modules are transported to the crossroad, assembled and fixed among themselves by special captures into a uniform construction, where sliding bearing parts lean on the road base (Figure 3).

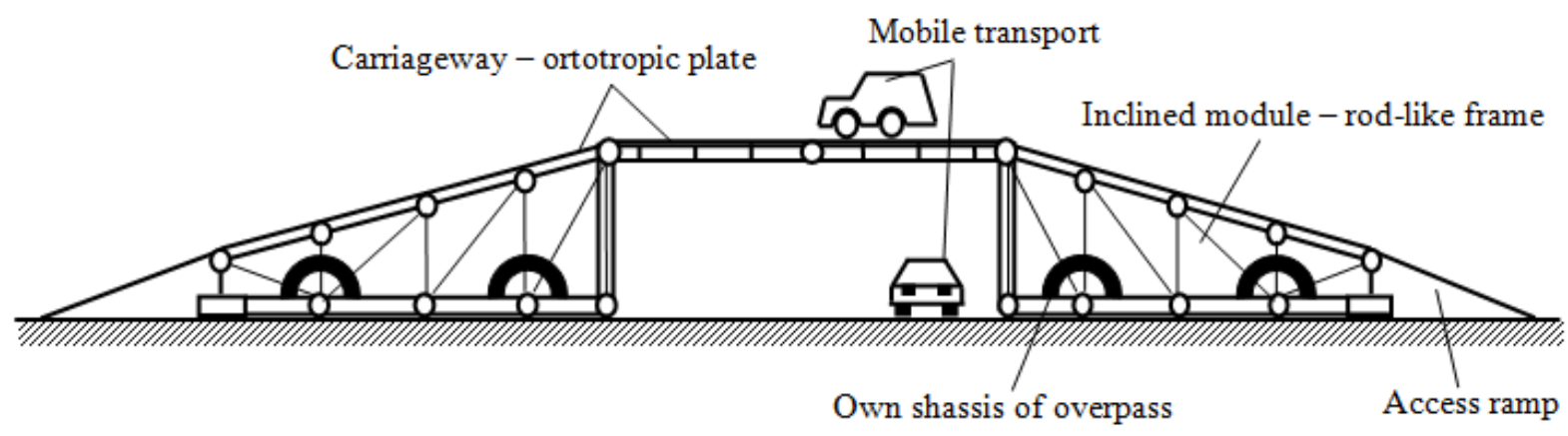

Figure 3. Mobile road overpass. Profile view (facade).

The road overpass has to meet dimensional conditions of a carriageway: journey height under them is not more than $4.5 \mathrm{~m}$, the width of a transport strip in one direction is not less than $3.5 \mathrm{~m}$ (for conditions of the Republic of
Kazakhstan). After elimination of a traffic block, the overpass is disassembled into several modules and towed to its base place. Operation of assembling and disassembling of the overpass is automated and it doesn't 
take much time due to its specially developed gears of fastening the overpass parts among themselves and a carriageway $[1,3]$.

The municipal overpass is used during repair or replacement of city municipal networks: thermal, water, cable, etc. The city municipal networks are usually located under highways. During their repair there is a separation of repair ditches and trenches on the place of highways that causes their blanking for a long time and need to organize various long inconvenient bypass roads.
It causes formation of traffic jams, worsens transport logistics of the city, increases accident rate level, etc.

In these conditions, instead of the compelled ways of bypass roads of municipal ditches and trenches we suggest to organize direct bridge crossings over them modular municipal overpasses. Such overpass is installed through repair ditches of municipal networks and allows not to stop transport streams near repair sections of roads for all the time of underground repair (Figure 4). The use of the municipal overpass naturally improves transport condition in the city.

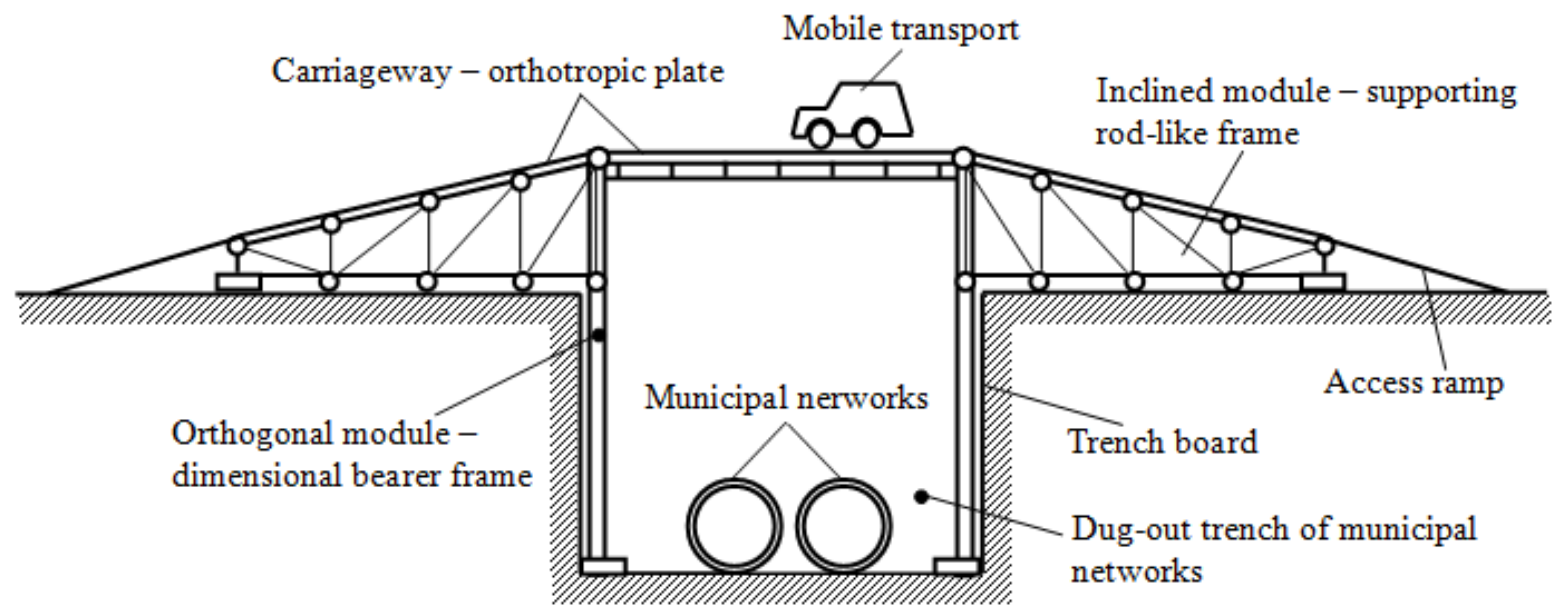

Figure 4. Modular municipal overpass. Side view (facade).

The municipal overpass assembled from the unified collapsible modules of two types: one orthogonal focused module and two inclined modules.

The orthogonal focused module represents a spatial steel frame which base is fastened at the bottom of a repair trench by means of special modes. The top part of the frame presents a carriageway in the form of orthotropic plate with the supporting reinforcement ribs .

The inclined module represents the steel rod-like frames bearing a carriageway on themselves in the form of ortotropic plate. The base of rod-like frames leans on the ground base, other part of rod-like frames leans on a bearer frame.

The linking of inclined modules with a bearer frame, allows to avoid loading on the edges of boards of repair trenches and reduces probability of their collapse while using the overpass. However the second basic devices of inclined modules are in power interaction with the natural ground base in this connection, there is a problem of additional research of deformed state of the intense ground massif and prevention of trench boards destruction [4].

Bridge moving is delivered to the installation site by separate modules and assembled in "one-way" or by hitch method in "two-way" construction.

Outline dimensions of "one-way" modules are the following: length of the orthogonal focused module $-8 \mathrm{~m}$; width - 3,5m; height (taking into account their installation at the bottom of trenches) $-5 \mathrm{~m}$.

The length of the inclined module $-4 \mathrm{~m}$; width $-3,5 \mathrm{~m}$; greater height $-2 \mathrm{~m}$; smaller height $-0,2 \mathrm{~m}$.
After use of the municipal overpass its disassembling into separate modules in places of "hitch" is made, and then they are delivered to the place of their storage.

\subsection{Theoretical bases of overpass calculation}

Our scientific group developed the scientific-theoretical bases of calculation and design of mobile and modular overpasses of various types including design decisions for creation of all its parts and nodes.

Space-planning and design solutions are developed for creation of the unified modules of the mobile bridge crossings providing the required bearing ability of its carriageway for the admission of the types and number of transport determined by norms of the automobile bridge building. In this case preliminary selection of forms and the sizes of lateral sections of the bearing constructions is also made to perform their further calculations.

The calculations of the orthotropic plates of the carriageway of bridge crossings by various numerical methods, such as the method of final elements, final differences and so forth are carried out.

The intense deformed condition of dimensional frames of the orthogonal focused modules of overpasses on the basis of calculations of power state is investigated by the analytical method of conveyances with formation of the general matrixes considering parametrical variability of geometrical and rigidity characteristics of bearing components of spatial frames [5].

It allows to carry out automatic calculation of similar frames for bridge crossings of various constructive solution and intention. Here the final selection of lateral 
sections of the bearing constructions of spatial frame on the basis of standard conditions of strength, rigidity and stability taking into account specific requirements is carried out for designs of automobile bridge building.

The work of the bearing flat statically indefinable rodlike frames of inclined modules of overpasses is investigated by analytical method of forces. Here, we studied the influence of rigidity characteristics of rod-like frame cores which changes are able to make an essential result on power and tension rod-like frame state in general.

Interactions of basic devices of the overpass with the natural ground base are investigated and the analysis of ground massif stress condition in the zone of trench boards is developed. On this basis practical bases of calculation for strength and stability of the corresponding volume of the ground massif which is under loading from pressure of basic devices of the overpass and the recommendation for prevention of their destruction in the process of the overpass use are developed.

Different types of bearing parts of overpasses, chassis constructions, gears of modules fastening are developed for which the corresponding patents and certificates of intellectual property are received [1].

For creation of the effective design solution of mobile overpasses, on the basis of the mathematical theory of optimization the methods of optimizing calculations for the purpose of minimization of metal consumption of designs are developed for reduction of their cost.

\subsection{Constructive decisions}

The bearing constructions of all types of overpasses are carried out from the strengthened brands of steel. The flooring of carriageway is carried out from sheet steel 20 $\mathrm{mm}$ thick. The cloth of carriageway is made of thin corrugated steel or rubber cloth for ensuring the required grip of tires of the motor transport.

Preliminary selection of lateral sections of bearing components of bridge crossing modules of all types is made on the basis of strength conditions, rigidity, stability with a sufficient stock taking into account possible overloads and dynamic effect of the movement on the carriageway of automobile stock. The size of bridge loadings is accepted under the terms of euronorms.

Geometrical and rigidity characteristics of the bearing constructions are generalized and provided to the leading parameters for the possibility of calculations of elements of demountable modules of different function and intention functions [5].

Resting of racks of orthogonal focused module of municipal overpass on the bottom of the dug-out ditches and trenches is made through fixed concrete piles racks.

\section{Conclusion}

The theoretical bases of calculations developed and described above, allow to design overpasses of various types on a practical basis, since the development of their constructive solution, selection of lateral sections of the bearing constructions under the terms of their strength, rigidity and stability taking into account various loadings: both static and dynamic, arising from the movement of the automobile stock on the carriageway. Using methods of optimum design allows to create economic and reliable designs of overpasses.

The theoretical and applied developments described in this work allow to receive reliable and economical decisions in design and constructing of practical mobile and modular bridge crossings.

\section{References}

1. K.G. Balabekova, A.S. Kadyrov, in Proceedings of the International scientific-practical conference "Integration of science, education and production basis for the implementation of the Plan of Nation: selected papers, vol 2. 241-243 (2015).

2. L. Tasci, N. Kuloglu. The Balt. J of R. and B. Eng., 6 (1), 23-29 (2011).

3. J. Hu. Mechanics of Sheet Metal Forming, 211 (2010).

4. A.B. Darkov. Structural mechanics. 656 (2010).

5. S.K. Ahmadiev. Teoreticheskie osnovy konstuirovanie mehanicheskoi inzhenerii. 99 (2010) 